\title{
Evropsko upravno pravo: trendi in izzivi
}

UDK: UDK: $342(4)$

\author{
Bojan Bugarič \\ Univerza v Ljubljani, Pravna fakulteta \\ bojan.bugaric@pf.uni-lj.si
}

\begin{abstract}
IZVLEČEK
Evropski model upravnega prava doživlja veliko pomembnih sprememb. Vplivi, ki povzročajo te spremembe, so zelo raznoliki. Med najpomembnejše sodijo globalizacija, razvoj posebne upravne strukture $v$ Evropski uniji in razcvet informacijske tehnologije. Zaradi vseh teh vplivov naj bi se evropski (kontinentalni) model upravnega prava $v$ zadnjih dvajsetih letih zelo spremenil. $v$ prispevku obravnavam spremembe $v$ evropskih kontinentalnih državah, ki naj bi temeljito spremenile obliko, organizacijo in način delovanja javne uprave in upravnega prava. $V$ prispevku obravnavam predvsem vpliv dveh dejavnikov na spremembe $v$ upravnem pravu: vpliv prava in prakse Evropske unije ter vpliv globalizacije na kontinentalni model upravnega prava. Nekateri avtorji zagovarjajo tezo, da sta omenjena vpliva tako zelo spremenila podobo klasičnega evropskega modela upravnega prava, da lahko govorimo o nastajanju novega modela upravnega prava v kontinentalni Evropi. Še več, zaradi različnih vzrokov naj bi se evropski model močno približal ameriškemu modelu upravnega prava. Nekatere bistvene sestavine evropskega modela naj bi se tako spremenile $v$ smeri ameriškega modela, da zaradi tega avtorji napovedujejo konvergenco oziroma približevanje v prihodnjem razvoju različnih modelov upravnega prava. Osrednja teza takšnih teorij je, da smo v Evropi priča nastajanju modela regulatorne države, ki se v svojih sestavinah in značilnostih zgleduje po ameriškem modelu upravnega prava. $V$ zaključku prispevek strnem $z$ oceno osrednje teze o amerikanizaciji evropskega upravnega prava in opozorim, da je takšna teza nedokazana in preveč splošna ter da med različnimi modeli, tako znotraj Evrope kot tudi med evropskim in ameriškim, ostajajo pomembne razlike. Upravno pravo tako ostaja še vedno močno $v$ domeni nacionalnega prava, politike in kulture.
\end{abstract}

Ključne besede: evropski model upravnega prava, regulatorna država, evropeizacija, ameriški model, upravno pravo, konvergenca modelov, nacionalna upravna kultura.

\section{Uvod: spremembe evropskega modela upravnega prava}

Evropski model upravnega prava doživlja veliko pomembnih sprememb. Vplivi, ki povzročajo te spremembe, so zelo raznoliki. Med najpomembnejše sodijo globalizacija, razvoj posebne upravne strukture $\vee$ Evropski uniji in razcvet informacijske 
tehnologije. Zaradi vseh teh vplivov naj bi se evropski (kontinentalni) model upravnega prava $\vee$ zadnjih dvajsetih letih zelo spremenil. $\vee$ prispevku obravnavam spremembe $\vee$ evropskih kontinentalnih državah, ki naj bi temeljito spremenile obliko, organizacijo in način delovanja javne uprave in upravnega prava, predvsem vpliv dveh dejavnikov na spremembe $v$ upravnem pravu: vpliv prava in politik Evropske unije ter vpliv globalizacije na kontinentalni model upravnega prava.

Nekateri avtorji zagovarjajo tezo, da sta omenjena vpliva tako zelo spremenila podobo klasičnega evropskega modela upravnega prava, da lahko govorimo o nastajanju novega modela upravnega prava v kontinentalni Evropi. Še več, zaradi različnih vzrokov naj bi se evropski model močno približal ameriškemu modelu upravnega prava. Zato nekateri avtorji govorijo o "amerikanizaciji evropskega upravnega prava. Nekatere bistvene sestavine evropskega modela naj bi se tako spremenile $v$ smeri ameriškega modela, da zaradi tega avtorji napovedujejo konvergenco oziroma približevanje $v$ prihodnjem razvoju različnih modelov upravnega prava. Osrednja teza takšnih teorij je, da smo $v$ Evropi priča nastajanju modela regulatorne države, ki se $\checkmark$ svojih sestavinah in značilnostih zgleduje po ameriškem modelu upravnega prava. Osnovne značilnosti takšnega modela naj bi bile: posredna, pravno uokvirjena uprava, ki ne temelji na diskrecijskem upravljanju družbe, ampak na posredni, legalistični upravi, ki družbo ureja predvsem prek pravnega okvira, znotraj katerega posamezniki bolj avtonomno sprejemajo odločitve; "razdržavljenje « državne uprave, kar pomeni prenos pooblastil in pristojnosti na različne nedržavne subjekte; naraščajoči pomen neodvisnih regulatornih teles, kot so agencije in komisije, ki naj bi bile bolj primerne za posredno upravljanje $v$ regulatorni državi; večja vloga pravic posameznika $v$ odnosu do državne uprave; močnejša, dejavnejša vloga sodstva pri nadzoru nad izvršilno-upravno vejo oblasti ter juridizacija pravil, ki urejajo odnose znotraj državne uprave. Vse te značilnosti so že dalj časa navzoče $v$ ameriškemu modelu upravnega prava, zato avtorji zaključijo s tezo o amerikanizaciji evropskega upravnega prava.

Prispevek je razdeljen na dva dela: $v$ prvem delu so prikazane spremembe $\vee$ evropskem modelu upravnega prava, $\vee$ drugem pa analiza obsega sprememb. $V$ zaključku prispevek strnem z oceno osrednje teze o amerikanizaciji evropskega upravnega prava in opozorim, da je takšna teza nedokazana in preveč splošna ter da med različnimi modeli, tako znotraj Evrope kot tudi med evropskim in ameriškim, ostajajo pomembne razlike. Upravno pravo tako ostaja še vedno močno $v$ domeni nacionalnega prava, politike in kulture. 


\section{Regulatorna država: nov model upravnega prava?}

\subsection{Primerjava evropskega in ameriškega modela regulacije}

Globalizacija ima pomemben vpliv na strukturo in delovanje državne uprave. Ker postaja vloga trga vse pomembnejša, nekateri avtorji govorijo o prevladi trga nad državo in njenim regulatornim aparatom (Vogel 1996, str. 2). Prevladujoča podoba o globalizaciji slednjo prikazuje kot dinamičen proces odpiranja svetovnih trgov blaga, kapitala, dela, storitev, znanja, kulture, in posledično zmanjševanja pomena nacionalnih meja $\vee$ globalni družbi. Ena od najpogosteje omenjanih tez je, da vse večja povezanost različnih delov sveta pomeni, da država ni več ključni oblikovalec nacionalne politike (Hirst, Thompson 1999, str. xii). Svetovni trgi so tisti, ki prevzemajo vlogo nacionalnih držav pri oblikovanju nacionalne politike. Vse pogosteje slišimo, da globalizacija pomeni konec intervencijske države, značilne za dolgo obdobje razvoja po drugi svetovni vojni (Garrett 1998, str.6). To vlogo naj bi danes država prepustila trgom, ki naj bi tako postali glavni motor družbenega razvoja. Umik države in čim hitrejša deregulacija, liberalizacija in privatizacija so glavni slogani zagovornikov takšne podobe nove globalne ekonomije. Edina preostala alternativa naj bi bil model prostega trga, utemeljen na zasebni pobudi ter čim manjši in podrejeni vlogi države. Ta vidik je najbolj razviden pri velikih spremembah $\checkmark$ načinu upravljanja javnih služb, kjer država prenaša velik del svojih pristojnosti na tržne subjekte, ki jih regulira prek neodvisnih regulatornih ustanov.

Ena od posledic takšne teorije globalizacije naj bi bila vedno večja konvergenca med različnimi družbenimi ureditvami (Berger, Dore 1996, str. 5). Ker je pot le ena, naj drugim družbam ne bi preostalo nič drugega, kot da tudi same prevzamejo edini uspešni model. Glavna težava večine evropskih držav naj bi bila v preobsežni vlogi države in premajhni vlogi trgov. Evropske politične in pravne institucije naj bi bile preveč toge, počasne in neučinkovite. Recept za spremembe je znan: obsežna reforma evropske države blaginje, privatizacija javnih služb in podjetij, privatizacije socialne mreže, krčenje obsega socialnih izdatkov.

Drugi pomemben dejavnik, ki sočasno in vzporedno z globalizacijo vpliva na nacionalne sisteme državne uprave evropskih držav, je pravni red Evropske unije. Tu gre za dva različna vpliva. Na eni strani pravila Evropske unije neposredno in posredno vplivajo na organizacijo in delovanje nacionalnih državnih uprav. Pravila EU postavljajo vsebinske standarde delovanja državnih uprav držav članic. Po drugi strani pa je tudi sama struktura Evropske unije temeljito vplivala na nacionalne sisteme državne uprave. Evropska unija je nastala kot politična integracija, utemeljena predvsem na močnih ekonomskih temeljih, kjer so ekonomske pravice in svoboščine dolgo imele absolutno prednost pred političnimi. T. i. "negativna integracija», utemeljena na štirih temeljnih svobodah gibanja, je pomembno vplivala na strukturo 
regulacije $\vee$ Evropski uniji (Streeck 1994). EU ni nikoli razvila svoje lastne izvršilne oblasti, ki bi bila po svoji vsebini in strukturi podobna izvršilni oblasti na nacionalni ravni. Sama izvršilna oblast je razdeljena med več institucij, predvsem med Komisijo in Svet, in tudi navzdol, vertikalno, kajti velikega dela odločitev EU ne izvršuje izvršilna oblast EU sama, pač pa vlade držav članic. Tako se tudi Evropska unija približuje modelu regulatorne države, utemeljene na posredni, legalistični regulaciji, kjer istočasno naraščata pomen in vloga neodvisnih regulatornih agencij, komisij, sodne veje oblasti ter vloga posameznika pred upravnimi organi.

Če je povojno obdobje minilo v znamenju rasti t. i. »intervencijske« države blaginje, s katero je država oziroma državna uprava pridobivala na obsegu in pomenu, potem naj bi bila za sedanje obdobje značilna obratna usmeritev: vloga neposredne državne regulacije naj bi se umaknila trgu, ki naj bi primarno (samo) urejal vse več področij, ki so še nedavno bila predmet državne regulacije. Glavne značilnosti intervencijske države so bile njena močna vloga pri makroekonomski regulaciji in prerazporejanju dohodka (Majone 1997, str. 141). Državna uprava je $v$ tem modelu sama neposredno posegala $z$ različnimi oblikami intervencije $v$ gospodarstvo in tudi neposredno prerazporejala narodni dohodek. Država je nastopala kot planer (načrtovalec), neposredni producent določenih dobrin in storitev in tudi kot delodajalec. Državna podjetja so bila zelo pogosta organizacijska oblika $v$ vseh evropskih državah. Pri makroekonomskemu upravljanju, kjer država ureja fiskalno, monetarno politiko, regulira trge dela in vodi industrijsko politiko, je za to obdobje značilna velika mera diskrecije države pri vodenju takšne politike. $V$ nasprotju z intervencijsko državo pa naj bi bile osnovne značilnosti regulatorne države manjši poudarek na diskrecijskem makroekonomskem upravljanju, omejena politika prerazporejanja dohodka in porast regulatornega upravljanja, katerega glavni namen je odprava t. i. napak trga (»market failures«), ki vključujejo odpravo monopolov, negativnih eksternalij, nepopolnih informacij in nepopolne ponudbe javnih dobrin. Sestavni deli novega modela regulatorne države so privatizacija, liberalizacija in deregulacija. Kot poudarja Majone, privatizacija, liberalizacija in deregulacija ne pomenijo odprave regulacije oziroma povratka k modelu »laissez-faire" države, ampak spremembo načina regulacije. Kajti ob deregulaciji se obseg regulacije ni zmanjšal, ampak povečal. Spremenila pa se je narava regulacije. Zato nekateri avtorji govorijo o tem, da sta deregulacija in re-regulacija tesno povezani. Deregulacija zato ne pomeni odprave regulacije, ampak predvsem manj restriktivno in togo regulacijo. Nove oblike regulacije so zato bolj posredne, okvirne, več naj bi bilo regulacije s splošnimi pravnimi pravili in manj direktne regulacije, ki jo neposredno in diskrecijsko izvršuje državna uprava. Zaradi takšnih velikih sprememb Majone govori o preobrazbi intervencijske države $\vee$ regulatorno (Majone 1997, str. 143). Takšna sprememba načina in obsega regulacije ima seveda pomembne posledice tudi za strukturo in način delovanja državne uprave. Majone pravilno opozarja, da globalizacija in pravo EU nista edina dejavnika, ki prispevata k takšnim strukturnim spremembam 


\section{Bojan Bugarič \\ Evropsko upravno pravo: trendi in izzivi}

državne uprave. Kamarck opozarja na štiri dejavnike, ki najbolj vplivajo na spremembe državne uprave v svetu: globalizacija in z njo povezana konkurenčnost v gospodarstvu, demokratizacija, informacijska revolucija in deficit pri rezultatih dela državnih uprav (Kamarck 2000, str. 232). Med temi dejavniki obstaja sicer tesna povezava, vendar jih je treba kljub temu ločevati in natančno preučevati vzročnost med posameznimi dejavniki in državno upravo.

Nova oblika regulatorne države naj bi temeljito spremenila način delovanja državnih uprav na evropski celini. Zato je pomembno pogledati, katere so bistvene sestavine nove strukture regulatorne države, kot tudi kakšne spremembe $v$ načinu upravljanja prinaša novi model regulatorne države. Pri načinu upravljanja je najbolj vidna sprememba tista, ki se nanaša na večjo formalizacijo in večjo vlogo prava pri delovanju javne uprave. To seveda ne pomeni, da nacionalne državne uprave $v$ Evropi niso pravno urejene ali da njihovo delovanje ni opredeljeno z zakoni. Tudi evropsko upravno pravo seveda izhaja iz temeljnega ustavnega in pravnega načela delovanja uprave, to je načela zakonitosti. Državna uprava pri svojem delu črpa svojo legitimnost iz zakonskih pooblastil, ki določajo njene pristojnosti in tudi sodni nadzor nad njenim delovanjem.

Kar se spreminja, je povečana vloga prava in formalnih pravil pri delovanju državnih uprav. Ali povedano drugače, če primerjamo slog upravljanja v ameriškem modelu upravnega prava $s$ kontinentalnimi ureditvami, lahko ugotovimo, da je $v$ prvem modelu vloga prava in formalnih pravnih pravil tako izrazita, da skoraj ni pomembnejšega vidika delovanja uprave, ki ne bi bil pravno reguliran. Na evropski celini pa je bil tradicionalno pomemben del upravnega delovanja izvzet iz zakonske (pravne) regulacije in prepuščen bodisi internim aktom uprave ali pa $\vee$ diskrecijsko odločanje uprave. Tako je na primer celoten postopek priprave in izdelave predpisov bolj ali manj prepuščen različnim internim pravilom. Včasih je svoboda uprave še večja in njeno delovanje $v$ tej fazi (priprave predpisov) sploh ni pravno urejeno. Celoten postopek priprave zakona praviloma ni obsegal pravil, ki bi $\vee$ ta proces neposredno vključevala javnost. $V$ ZDA pa je tako rekoč vsak korak pri pripravi regulacije urejen natančno s predpisi in zato tudi predmet zelo stroge in intenzivne presoje s strani sodišč. Kagan zato govori o "antagonističnem legalizmu« (»adversarial legalism «) kot tisti sestavini, ki prežema ameriški model regulatorne države in prava nasploh (Kagan 2003, str. 187). Ta vidik se kaže predvsem v stalni in pogosti uporabi prava in sodišč kot najmočnejšem nadzoru delovanja uprave. Bistvena razlika med ameriškim "antagonističnim legalizmom " in evropskim "kooperativnim modelom « regulatorne države je v tem, da se v Evropi sodni nadzor in močnejša vloga prava pojavi kasneje $\vee$ procesu nastajanja regulatornih pravil. Za evropske modele je značilno, da niso od samega začetka upravnega procesa tako zelo pravno formalizirani, odprti za sodelovanje interesnih skupin, po svoji naravi manj konfliktni in bolj kooperativni ter manj pogosto predmet sodne presoje s strani sodišč. V Evropi 
se sodna presoja praviloma začne šele $v$ tistem trenutku, ko uprava s svojim delovanjem poseže $v$ katero od posameznikovih ustavnih pravic ali svoboščin. Do tega trenutka pa je njeno delovanje bolj ali manj diskrecijsko, urejeno zelo skopo in okvirno ter tudi manj odprto za sodelovanje širše javnosti.

Evropsko upravo pravo poudarja predvsem materialno zakonitost (načelo zakonitosti), ki terja vsebinsko usklajenost aktov uprave z zakonodajo, ameriško upravno pravo pa poleg prve izrazito poudarja tudi procesno zakonitost, ki se kaže $\checkmark$ natančni pravni urejenosti skoraj vsakega najmanjšega vidika delovanja uprave. Vogel v pomembni študiji celo za Veliko Britanijo, sicer zibelko common lawa, ugotavlja, da je njen model regulacije veliko bolj prožen, neformalen, kooperativen in manj odprt za sodno presojo, ki je tudi bolj redka, kot ameriški model. Zaradi tega pravniki nimajo tako velike vloge pri oblikovanju predpisov kot $\vee$ ZDA (Vogel 1986). Kot pravilno ugotavlja Wilson, evropsko kontinentalno pravo ne dopušča državljanom, da bi sooblikovali politiko regulacije. Posameznik se lahko vključi v oblikovanje pravil šele takrat, ko uprava krši katero od njegovih pravic (Wilson 1989, str. 298). Tudi sodstvo je praviloma bolj "prijazno" do uprave in ne posega v vsebinsko presojo politike regulacije. Tradicionalni sodni nadzor uprave je na kontinentu omejen na nadzor nad zakonitostjo upravnih predpisov in posamičnih aktov. V ZDA pa sodstvo pogosto posega tudi v samo politiko regulacije (»policy formulation «), saj ima skoraj neomejena pooblastila za presojo delovanja upravnih organov. Ker je procesna zakonitost zelo pomembna, lahko sodstvo presoja zakonitosti samega postopka oblikovanja upravnih predpisov. S sprejetjem zakona o upravnem postopku ("Administrative Procedure Act", v nadaljevanju APA) leta 1946 je bil v ZDA postavljen nov model upravnega prava. Pred tem, še posebej $\vee$ obdobju programa New Deal, so bile tudi za ZDA značilne številne lastnosti, ki jih danes pripisujemo le evropskemu kontinentalnemu pravu. Sprejetje APA pa je ameriški upravni proces temeljito spremenilo in premaknilo v smer "antagonističnega legalizma». Ameriška upravna doktrina in teorija je osrednjo pozornost preusmerila na procesno zakonitost delovanja uprave. Ta proces je odlično opisal Stewart (Stewart 1975) $\vee$ še danes najbolj vplivnem članku o ameriškem upravnem pravu. Upravna teorija je spoznala, da je nemogoče oblikovati tako popolne zakone, ki bi že sami, po načelu zakonitosti, $v$ celoti določali vsebino upravnega delovanja. Sledilo je sprijaznjenje z dejstvom, da je diskrecija nujna sestavina upravnega odločanja. Da pa diskrecijsko odločanje ne bi poseglo v temelje ustavne doktrine, predvsem načela delitve oblasti, je ameriška doktrina in zakonodaja diskrecijsko odločanje utesnila $v$ stroge procesne modele formalnega odločanja. Zato izdajanje upravnih predpisov s strani ameriških agencij evropskega opazovalca spominja na pravi sodni postopek z vsemi procesnimi kavtelami in pravicami strank $\vee$ takšnem postopku. Naj tu omenim, da je bila takšna sprememba seveda pogojena s prakso upravljanja ameriške družbe, ko je obseg regulacije neprestano naraščal in ko je vse bolj postajalo jasno, da zakonodajalec ne more popolnoma uokviriti dela regulatornih agencij. Politično in pravno gledano 


\section{Bojan Bugarič \\ Evropsko upravno pravo: trendi in izzivi}

to pomeni, da so agencije bolj samostojne pri oblikovanju regulatorne politike, saj jim zakoni pogosto dajejo zelo splošna in okvirna zakonska pooblastila. Zaradi natančnosti je treba dodati, da to ne drži v vseh primerih in na vseh področjih regulacije. Zelo pogost je prav nasproten primer, ko so zakoni zelo obsežni, natančni, kompleksni in velikokrat tudi nejasni in težko izvršljivi. Prav to pa zahteva precejšnjo mero ustvarjalnosti agencij pri prilagajanju zakonodajalčevih ciljev dejanskim družbenim razmeram. Kot ugotavlja ameriški vrhovni sodnik Scalia, je delegacija v ameriškem upravnem pravu praviloma zelo široka in upravnim agencijam pogosto daje pooblastila sprejemanja predpisov, ki so podobna zakonodajnim pooblastilom (Schwartz 1991, str. 42). Pregled vezanosti uprave na zakon v evropskih kontinentalnih državah razkriva, da je stopnja vezanosti močnejša, in posledično, da je obseg delegacije manjši (Šturm 1998).

Kagan nadalje ugotavlja, da je za ameriško regulatorno državo značilno, da je bolj legalistična tudi pri implementaciji predpisov $\vee$ praksi, kar pomeni, da pogosteje uporablja pravno predpisane sankcije, ki so praviloma precej višje kot $v$ evropskih državah. Naj kot primer omenim, da je za »insider trading " $\vee$ borznem pravu predpisana kazen do enega milijona dolarjev za posameznike ter do dveh in pol milijonov dolarjev za pravne osebe, za kršitev zakonodaje o vrednostnih papirjih pa zaporna kazen od 5 do 10 let. $\vee$ Kaliforniji je za kršitev predpisov o varstvu voda predpisana kazen $\vee$ višini enega milijona dolarjev (sic!). $\vee$ nasprotju s takšno podobo pa evropske države težijo k bolj neformalnemu in manj kaznovalnemu pristopu, kjer upravni inšpektorji zgolj "opozarjajo" na kršitve in "svetujejo" upravi, naj takšne kršitve odpravi (Kagan 2003, str. 187).

Tudi odnos med državno upravo in subjekti, ki so predmet regulacije, je $v$ obeh modelih zelo različen. $V$ ZDA je ta odnos legalističen in antagonističen ter predmet zelo pogostih sodnih sporov in presoj. Posameznik ima $\vee$ ZDA bistveno lažji dostop do sodišč pri sprožanju sodne presoje. Aktivna legitimiranost je razširjena prek doktrine pravnega interesa (»standing «), ki ga ameriška sodišča razlagajo zelo široko. številni področni zakoni sploh širijo aktivno legitimacijo in zahtevajo zgolj dokaz, da je bila z aktom uprave povzročena določena dejanska škoda (»injury in fact «) (Bugarič 1995). V kontinentalnem upravnem pravu je bistveno teže postati "stranka v postopku", saj mora posameznik dokazovati kršitev svojih pravic ali pravnih koristi. Opredelitev pravnega interesa so ameriška sodišča namenoma širila, saj so hotela zagotoviti čim večjo odprtost sodnega postopka za posameznike. Posameznik ima $\vee$ ZDA pravno varovano pravico do konzultacije pri nastajanju upravnih predpisov. Gre za tako imenovani "notice and comment" postopek, ki ga ureja APA. Vsak državljan ima pravico posredovati svoje mnenje o predlaganem predpisu, agencije pa morajo $\vee$ predpisanem roku na takšna mnenja državljanov tudi odgovoriti. Celoten postopek je natančno urejen in daje državljanom močna procesna zagotovila za sodelovanje pri pripravi predpisov. Nespoštovanje teh pravil 
nadzira sodna veja oblasti in zelo intenzivno posega $v$ delo agencij. Ker je nemalokrat nemogoče ločiti med procesnim vidikom, ki je predmet pravnega varstva, in vsebino regulacije, sodišča tako pogosto posegajo $v$ samo oblikovanje politike uprave, kar naj bi bilo strogo izvzeto iz njihove pristojnosti, če bi upoštevali načelo delitve oblasti. $\vee$ evropskih kontinentalnih državah je postopek sodelovanja urejen drugače, saj državljani praviloma nimajo pravno urejene možnosti, da bi sodelovali že pri pripravi predpisov. $\vee$ nekaterih državah sicer obstaja praksa redne konzultacije s civilno družbo, ki pa ni pravno urejena. Praviloma pa pri pripravi predpisov sodelujejo le strokovnjaki ali predstavniki organiziranih interesov, ne pa širša javnost.

Zelo drugačen je tudi odnos med političnimi organi in upravo. V ZDA je zelo pogosta intervencija kongresnih odborov, političnih strank in politike nasploh $v$ samo regulacijo. Tudi politizacija uprave je bila $\vee$ ZDA tradicionalno bolj intenzivna kot $\vee$ evropskih državah, saj je bil sistem plena (»spoils system«) dolgo pravilo pri kadrovanju državne uprave. $\vee$ večini evropskih kontinentalnih držav je bila uprava profesionalna, nepolitična, kar je zmanjševalo potrebo po tako obsežnem procesnem in sodnem nadzoru nad njenim delom. V ZDA je zelo poudarjena vloga kongresnih odborov, ki z veliko mero ekspertize zelo natančno in pogosto spremljajo delo upravnih agencij in pogosto zahtevajo spremembe njihovih odločitev. $V$ Evropi je manj "tekmovalnosti « med zakonodajno in izvršilno vejo oblasti, kar je pogojeno tudi z drugačno strukturo same oblasti in drugačnega modela delitve oblasti. $V$ evropskih državah je $\vee$ večini primerov vlada tudi gospodar razmerij $\vee$ parlamentu, kar pomeni, da je njeno vladanje manj obremenjeno z nadzorno vlogo parlamenta (Wilson 1989, str. 298).

\subsection{Naraščajoča vloga posredne regulacije in agencij}

Kot sem omenil že pri opisu preobrazbe intervencijske države $v$ regulatorno, naj bi bila glavna značilnost regulatorne države manj direktno obdavčevanje in poraba proračunskega denarja kot pa sprejemanje pravil (rule-making). Najbolj primerne institucije za sprejemanje takšnih pravil pa so neodvisne regulatorne komisije in agencije, ki so obenem dovolj prožne, visoko specializirane in avtonomne od politike. Zato $v$ regulatorni državi narašča vloga neodvisnih regulatornih agencij in komisij. Krepitev regulatorne vloge je tesno povezana s privatizacijo javnega sektorja. Nekdaj tradicionalen model javnega sektorja, $v$ katerem so prevladovala državna (javna) podjetja na področju javnih služb, se je izkazal ponekod za precej neučinkovitega. Sledila je bolj ali manj radikalna privatizacija javnih služb, ki pa jo je spremljala ustanovitev novih regulatornih teles, praviloma ustanovljenih z zakonom. Tako ustanovljene neodvisne regulatorne agencije oziroma komisije pa niso več neposredno upravljale javnih služb. Način regulacije se je spremenil. Značilnost novega načina regulacije prek neodvisnih javnih agencij je okvirnost in posrednost 


\section{Bojan Bugarič \\ Evropsko upravno pravo: trendi in izzivi}

njihove regulacije. Agencije postavljajo pravila igre in tudi razsojajo $v$ konkretnih primerih znotraj teh pravil igre, ki pa so praviloma splošna in okvirna. Regulacija je na ta način ločena od neposrednega upravljanja javnih služb in javnih podjetij. Zelo pomembna je pravna in politična neodvisnost novih regulatornih agencij, ki so ustanovljene kot pravne osebe javnega prava, neodvisne od državne uprave in tudi organizacijsko strukturirane zunaj klasičnega resornega načela. število neodvisnih regulatornih agencij $\vee$ Evropi sicer narašča, ne pa povsod in enakomerno (Thatcher, Stone Sweet 2002). Razvoj agencij v Evropi je dokaj postopen in ponekod precej počasen, odvisen tako od nacionalnih upravnih sistemov kot tudi od politične kulture $\checkmark$ državi. Nekatere države so zelo pohitele z ustanavljanjem neodvisnih regulatornih agencij, druge so nekoliko bolj previdne. Tudi sam ustroj in pravni status agencij nista povsod enaka. Shapiro opozarja, da ima $\vee$ ZDA pomembno vlogo pri nadzoru agencij zakonodajalec, ameriški Kongres, kar praviloma ni značilno za agencije $\vee$ evropskih državah. Različni avtorji tudi opozarjajo na določene razlike med vrstami neodvisnih regulatornih agencij, ki kljub enakemu poimenovanju niso enako organizirane.

Tudi uspešnost in učinkovitost delovanja agencij nista povsod enaki. Ponekod so te bolj uspešne, drugod smo priča tudi obratnim trendom, kjer agencije ponovno vključujejo v klasične ministrske oddelke. Takšen je primer Danske. Agencije imajo ponekod specifično, krajevno tradicijo, ki ni primerljiva z ameriškim modelom. Takšen je primer Švedske, kjer so agencije sestavni del švedskega modela države uprave (Ziller 2001). Tudi švedski model agencij, najstarejši v Evropi, se sooča z določenimi problemi. Trenutno na Švedskem veliko pozornosti namenjajo problematiki usklajevanja dela med tako številnimi agencijami.

\subsection{Razdržavljanje države}

Druga pomembna značilnost oziroma sprememba $\vee$ državni upravi je zmanjšanje obsega, sredstev in velikosti javnega sektorja v evropskih državah (Wright 1994, str. 110). Številne države so zmanjšale število zaposlenih $v$ državni upravi, Finska npr. za $5 \%$, Švedska za $10 \%$ (načrt), Velika Britanija za 7,3 \% v šestih letih. Pomembno se zmanjšujejo tudi finančna sredstva, namenjena državni upravi, čeprav nekateri opozarjajo, da zmanjšanje deleža BDP, ki ga države namenijo za javni sektor, še vedno ni tako drastično, kot nekateri prikazujejo (Garrett 1998: 137). Obseg javnega sektorja se je zmanjšal predvsem s privatizacijo na področju industrije, kjer prednjačita Velika Britanija in Francija. Privatizacija kot celoten prenos dejavnosti na zasebni sektor je nekoliko manj izrazita na področju javnih služb in socialne države. Obseg javnega sektorja se zmanjšuje tudi prek deregulacije. Zelo pomemben del tega procesa je debirokratizacija, ki pomeni odpravo nepotrebnih pravil in predpisov. Med prvimi je takšen proces začela Nemčija, sledile so ji številne druge 
države. Na Portugalskem, ki je na tem področju naredila pomembne premike, je v 90. letih vlada Cavala Silva celo ustanovila nacionalni dan za debirokratizacijo, da bi pokazala resen namen spopasti se s tem problemom.

Posebej zanimiv in pomemben trend pri reformi državne uprave je privatizacija upravljanja javnih služb. Privatizacija na področju javnega sektorja ima lahko različne oblike in pomene. Privatizacija lahko pomeni predvsem pravno, tj. lastninsko spremembo, kar vključuje prodajo celote ali deleža državnih podjetij zasebnikom. Privatizacija pa lahko pomeni tudi "zgolj» privatizacijo dejavnosti v obliki koncesij oziroma "contracting out", kjer država pogodbeno prenaša izvajanje določenih javnih služb na zasebne izvajalce. Zelo povezana s privatizacijo je konkurenčnost, čeprav oba pojma nista nujno medsebojno povezana. Iz literature je znana ugotovitev, da privatizacija sama po sebi, zgolj kot sprememba lastništva, še ne pomeni nujno tudi povečanja konkurenčnosti. Privatizacija $v$ nekonkurenčnem okolju lahko pomeni zgolj preoblikovanje javnega $\vee$ zasebni monopol. Za vzpostavitev konkurenčnosti so pomembni še drugi dejavniki, ki ne izhajajo neposredno iz same lastniške oblike upravljanja. Pregled literature na tem področju pokaže, da ni dovolj dokazov za tezo o superiornosti zasebne nad javno lastnino. Študije kažejo, da lahko privatizacija $v$ določenih primerih prispeva $k$ večji učinkovitosti. Iz takšne ugotovitve pa ne moremo zaključiti, da je zasebna lastnina vedno superiorna nad javno. Izkušnja razvitih industrijskih držav je, da privatizacija javnih služb ni zadosten pogoj za njihovo uspešnejše delovanje. Ena od glavnih ugotovitev raziskav privatizacije javnih služb v Evropi, Angliji in ZDA je, da je za zagotovitev kvalitetnejšega delovanja teh služb bolj kot sama lastninska preobrazba pomembna konkurenčnost med izvajalci javnih služb.

Tudi obseg privatizacije je $v$ različnih državah in sektorjih zelo različen. Prednjačita Velika Britanija in deloma Francija, kjer je prišlo do najbolj obsežne privatizacije državnih podjetij. Od področij regulacije so telekomunikacije gotovo tisto področje, kjer je privatizacija najbolj pogosta. Na drugi strani pa javna lastnina še vedno prevladuje na področju železniškega prometa $\vee$ Franciji in Nemčiji, medtem ko je položaj $\vee$ Veliki Britaniji drugačen, vendar tudi tam ni enosmeren (primer Railtrack). Tudi na področju telekomunikacij država ohranja precejšnje deleže $v$ podjetjih, kot so France Telecom (54 \%) in Deutsche Telekom (42 \%). Ta zadnja primera predstavljata "nepravo « privatizacijo oziroma korporativizacijo javnih podjetij, ki tudi zmanjšuje neposredni vpliv države na javne službe, vendar še zdaleč ne pomeni popolnega umika države s tega področja. Tu gre za preoblikovanje javnih podjetij v navadne gospodarske družbe. Korporativizacija se je izkazala za uspešno strategijo $\checkmark$ številnih primerih. Pomeni ločitev regulativne od menedžerske funkcije, ki pa ni nezdružljiva z bolj ali manj močno kapitalsko navzočnostjo države $v$ takšni delniški družbi. 


\section{Bojan Bugarič \\ Evropsko upravno pravo: trendi in izzivi}

Pregled privatizacije kaže, da so njeni učinki manj jasni od same ideologije privatizacije, ki zasebno lastnino predstavlja kot edino možno učinkovito obliko upravljanja. Čeprav t. i.statična učinkovitost na kratki rok narašča, so dokazi o dinamični učinkovitosti veliko manj jasni (Parker 1999, str. 25). Do podobnih ugotovitev pride Hodge, ki v obsežnem primerjalnem pregledu literature o privatizaciji ugotovi, da še zdaleč ni dokazov o superiornosti zasebne nad javno lastnino (Hodge 1996).

\subsection{Decentralizacija}

Naslednji pomemben način zmanjševanja obsega javnega sektorja je tudi decentralizacija, ki pomeni prenos pristojnosti z državne ravni na regionalno ali občinsko raven. Trend decentralizacije je izrazito narasel $v$ zadnjih 15 letih. Vključitev načela subsidiarnosti $v$ pravo EU pa je temu procesu dala še poseben pomen. Kot opozarja Pollitt, sama funkcionalna in teritorialna decentralizacija ni brez lastnih problemov. Tako funkcionalna kot teritorialna decentralizacija izhajata iz predpostavke, da bo vertikalno nižja oziroma horizontalno bolj avtonomna enota bolje opravljala funkcije upravljanja kot prejšnji center oziroma ministrstvo. To pa ni vedno nujno res. Kot poudarja Pollitt, decentralizacija lahko vodi k večji učinkovitosti. Ali je učinkovitost dejansko dosežena, pa je odvisno od številnih drugih dejavnikov (Pollitt 2003).

Decentralizacija naj bi omogočila lokalne inovacije, približala upravo neposredno državljanom, politike naredila bolj odgovorne in vidne navadnim državljanom. Kompleksnost sodobne regulacije naj bi onemogočala kvalitetno centralno državno upravljanje. Kljub številnim dosežkom pa ni mogoče zaključiti, da je prenos pristojnosti z državne na lokalno raven nujno pot $k$ uspehu in boljšemu upravljanju. Odnos med decentralizacijo in centralizacijo se zgodovinsko gledano ciklično spreminja, saj obdobjem večje priljubljenosti centralizacije sledijo obdobja zaupanja v lokalne oblasti in obratno (Pollitt 2003). Z vidika enakosti državljanov pred zakonom je centralizacija pogosto pomenila prispevek k izboljšanju njihovega položaja. Devolucija pristojnosti ameriškim zveznim državam je $\vee 60$. letih prejšnjega stoletja močno utrdila prakso rasne segregacije. Šele močna zvezna zakonodaja je omogočila nastanek razmer za vzpostavitev rasne enakosti $\vee$ ZDA. Tudi $\vee$ Franciji številni enačijo decentralizacijo s socialnim nazadovanjem, neenakostjo državljanov in celo povratkom $v$ obdobje pred Republiko. Zagovorniki republikanske ureditve enačijo teritorialno enovitost z napredkom, enakimi možnostmi in skupnim državljanstvom. Kot opozarja eden od vodilnih analitikov upravljanja $\vee$ ZDA, je centralizacija ponavadi odgovor za preveč decentralizirane sisteme in obratno. Celo več, oba trenda se pogosto pojavljata simultano, kar pomeni, da je določen delež decentralizacije dobro dopolniti s centralizacijo ali obratno. Zaradi takšne kompleksnosti je vsakršna absolutna ocena o prednostih decentralizacije poenostavitev. Ali decentralizacija lahko

\section{Uprava, letnik II, 2/2004}


izboljša kakovost upravljanja, je spet odvisno od vrste drugih dejavnikov, kot so menedžerske in politične sposobnosti upravljavcev, velikost organizacije (premajhna enota lahko onemogoči "ekonomijo obsega" in dobro upravljanje), tehnična kompleksnost prenesene naloge kot tudi vrste programov, ki jih prenašamo. Določene vrste nalog in programov je laže upravljati na lokalni ravni (npr. manj standardizirane in bolj kompleksne naloge). Decentralizacija tudi vedno pomeni nujnost izbire med več različnimi političnimi cilji in vrednotami. Npr. čeprav decentralizacija približa storitve uporabnikom, po drugi strani vodi do večje neenakosti pri zagotavljanju storitev. Partnerstvo med državo in lokalno upravo lahko sicer izboljša učinkovitost servisa, lahko pa obenem zmanjša preglednost upravljanja in tudi jasno linijo odgovornosti za rezultate upravljanja. Le Gales v študijah o regijah opozarja, da regije niso ključni instrument ekonomskega razvoja. Opozarja na šibko institucionalizacijo regij $\vee$ državah, kot so Irska, Portugalska in skandinavske države, in dokazuje, da države, ki imajo regionalno strukturo, niso nujno ekonomsko uspešnejše (John 2001, str. 122). Bolj kot formalna struktura je pomembna de facto razvojna regionalna politika, ki lahko uspeva $v$ državah z unitarno ali decentralizirano strukturo.

Druge, nič manj pomembne spremembe, ki pa jih v prispevku ne obravnavam, vključujejo reforme proračunskih, evaluacijskih in načrtovalnih postopkov državne uprave, reforme upravljanja državne uprave, reformo klasične »karierne« uslužbenske zakonodaje, demokratizacijo državne uprave, uvedbo uporabniku prijazne uprave, reorganizacijo strukture državne uprave, spremembo kulture državne uprave (Wright 1994).

\subsection{Močnejši sodni nadzor}

Zaradi poudarka na novi obliki regulacije, ki je bolj okvirna, posredna in splošna, narašča tudi vloga sodstva, ki nadzoruje pravno pravilnost takšne regulacije. Ker je nova oblika regulacije manj diskrecijska in hierarhična, je za spoštovanje splošnih pravil, ki jih sprejemajo agencije in druge komisije, odgovorno sodstvo. Narašča vloga sodne presoje takšne vrste regulacije oziroma pravil, ki so produkt takšne regulacije. $\vee$ Evropi je pri tem trendu še posebej pomembna vloga Evropskega sodišča pravice, ki je s svojo sodno prakso izoblikovalo številne standarde, ki veljajo na tem področju in se uporabljajo $v$ vseh članicah EU. Majone poudarja, da je slog regulacije $v$ novem modelu, ki ga opisuje, izrazito legalističen, oprt na pravila, in posreden. Glavni akterji v takšnem novem modelu naj bi bili predvsem pravniki, sodniki, neodvisni strokovnjaki, regulatorji. $V$ regulatorni državi torej ne narašča zgolj pomen sodstva in agencij, pač pa prava in pravnikov nasploh. Obenem pa je treba povedati, da se oblike sodne presoje, načini pravne argumentacije in organizacija sodstva še vedno precej razlikujejo med različnimi državami. Britansko sodstvo je veliko manj agresivno pri nadzoru državne uprave kot ameriško. Po drugi strani pa 
Bojan Bugarič

Evropsko upravno pravo: trendi in izzivi

je francoski Državni svet, najvišje upravno sodišče, razvil zelo bogato prakso sodnih precedensov, s katerimi je postavil temeljna načela delovanja uprave. Eno od takšnih zanimivih področij je odškodninska odgovornost države za svoje nezakonite in škodljive akte. Francoski Državni svet je na tem področju izoblikoval zelo moderno javno odškodninsko pravo, ki je $v$ celoti zajeto $v$ odločbah sodišč.

\subsection{Varstvo pravic posameznikov.}

$S$ tem trendom je povezan tudi trend naraščanja vloge posameznika nasproti državi. Posameznik ima na voljo vse več pravnih sredstev, s katerimi lahko varuje svoje pravice pred posegi državne uprave. Prav zaradi tega dejstva Harlow govori o spremembi instrumentalnega modela upravnega prava $v$ kontrolni model upravnega prava (Harlow 1998, str. 264). Pri prvem modelu je osrednja pozornost upravnega prava namenjena predvsem učinkovitemu delovanju države. Takšen model je značilen za evropsko celino, ni pa se uveljavil $v$ anglosaških državah, kjer je ves čas prevladoval kontrolni model upravnega prava, katerega glavni cilj je zaščita posameznika pred nezakonitimi in neupravičenimi posegi države. Ta razlika se mogoče najbolj nazorno kaže $v$ ostri zavrnitvi posebnega upravnega prava in posebnih upravnih sodišč $\checkmark$ anglosaških državah. Angleški ustavni teoretik Dicey je bil najbolj znan nasprotnik francoskega modela upravnega prava, ki je kasneje postal vzor za večino kontinentalnih evropskih držav. Dicey je zavračal uvedbo posebnih upravnih sodišč in posebne veje prava, upravnega prava, z argumentom, da bi takšna posebna sodišča ogrozila samo bistvo angleškega prava, to je "the rule of law" (Dicey 1915, str. 213). Zato je še danes upravno sojenje del redne sodne funkcije in večina anglosaških držav prav tako ne pozna posebnih upravnih sodišč. Vendar prav primer francoskega Državnega sveta kaže, da je takšna ocena pretirana, saj je bogata sodna praksa francoskega najvišjega upravnega sodišča pomembno sredstvo varstva pravic posameznika pred državo. Podobno velja tudi za nemški sodni nadzor nad upravo, ki je tradicionalno zelo močan.

Posameznik pridobiva tudi druge pomembne pravice, ki so povezane z delovanjem državne uprave. Gre za različne oblike pravic, ki jih uvrščamo v področje »odprte uprave«. Gre za pravico do dostopa do informacij javnega značaja, pravico do sodelovanja pri sprejemanju upravnih predpisov in odločitev ter pravico do soodločanja pri nekaterih javnih zadevah. Tipična značilnost evropskega upravnega prava, tj. instrumentalnega modela, je bila, da posameznik ni bil vključen $v$ sprejemanje upravnih odločitev. To se danes zelo spreminja. Državna uprava je dolžna prek različnih postopkov posameznika vključiti $\vee$ sprejemanje splošnih upravnih aktov. "Notice and comment" postopek, značilen za ameriško upravno pravo, pridobiva na pomenu tudi v Evropi. Takšno ali drugačno različico tega postopka je uvedlo že nekaj evropskih držav. Tako da danes posamezne države tudi v svojih pravnih redih

\section{Uprava, letnik II, 2/2004}


priznavajo posamezniku pravico do sodelovanja pri sprejemanju splošnih in včasih tudi konkretnih upravnih aktov. Tu so najbolj opazne spremembe pri pravu varstva okolja in pravu varstva potrošnikov, kjer se je ta praksa najprej pojavila. Ta vpliv pa se počasi širi tudi na druga pravna področja in pridobiva značaj priznanega načela upravnega prava. Celo novi osnutek Evropske ustave uvršča načela odprte uprave $\checkmark$ posebno pravico, pravico do dobre administracije. Tudi notranji procesi znotraj uprave so vse pogosteje podvrženi regulaciji, kar pomeni precejšnjo spremembo v evropskem modelu in približevanje $\mathrm{k}$ ameriškem modelu. Tu gre za pravno urejene postopke analize učinkov predpisov (RIA), za postopke, ki urejajo nastajanje pravil oziroma regulacije znotraj uprave in drugih pravil.

\section{Amerikanizacija evropskega modela upravnega prava?}

Globalizacija naj bi torej pripeljala do korenite spremembe $v$ vsebini in strukturi moderne regulacije, zaradi česar Majone in nekateri drugi avtorji govorijo o preobrazbi »intervencijske« države v »regulatorno". Pri tem kaže opozoriti, da globalizacija res temeljito spreminja tako vsebino oblike regulacije kot tudi pravne in politične institucije sodobne državne uprave. Po drugi strani pa analitiki globalizacije opozarjajo, da globalizacija ni povsem enosmeren proces s povsem jasno začrtano smerjo razvoja. Analitiki regulacije opozarjajo, da večji vpliv trgov ne pomeni nujno tudi manj regulacije. Vogel v pomembni študiji opozarja, da globalizacija, deregulacija in privatizacija sicer pomenijo manj posredne regulacije, značilne za obdobje 60. in 70. let, obenem pa globalizacija vodi do re-regulacije na novi ravni: neposredno regulacijo nadomeščajo nove oblike regulacije, ponavadi bolj posredne, kar pa ne zmanjšuje pomena regulacije (Vogel 1996).

Analize nacionalnih sistemov državne uprave tudi kažejo, da kljub globalizacijskim trendom med posameznimi državami še vedno obstajajo pomembne razlike tako pri vsebini regulacije kot pri strukturi državne uprave. Globalizacija pomembno spreminja državno upravo, vendar ta proces poteka $v$ različnih državah različno. Pomembne študije opozarjajo na različne nacionalne "sloge« regulacije, ki ostajajo kljub močnim globalizacijskim pritiskom (Vogel 1986). Celo v skupnem evropskem prostoru, ki je povezan s pravom EU, avtorji opozarjajo, da se sicer skupna evropska pravila izvršujejo v različnih državah na različne načine, kar pa ne ogroža nujno enovitosti prava EU .

Kontrolni model upravnega prava, ki pridobiva na pomenu tudi v Evropi, pa ni v vseh svojih sestavinah nekaj, kar bi bilo najbolj značilno za kontinentalno gledanje na upravno pravo. Nasprotno, $v$ Evropi je dolgo prevladoval t. i. instrumentalni pogled na upravno pravo, kjer je bil poudarek na čim hitrejšem in učinkovitejšem delovanju izvršilne oblasti najbolj jasno razvit $v$ francoskem upravnem pravu. Z 
Bojan Bugarič

Evropsko upravno pravo: trendi in izzivi

opisanimi spremembami pa se tudi Evropa vse bolj usmerja $v$ kontrolni model upravnega prava, kjer je glavni poudarek na zaščiti pravic posameznika in sodnem (pravnem) nadzoru delovanja upravnega aparata. Takšen pogled na upravno pravo je značilen predvsem za anglosaški pravni prostor. Zaradi tega vse več avtorjev govori o močnem vplivu anglosaškega upravnega prava na kontinentalno upravno pravo. Te spremembe, spodbujene z globalizacijo in evropeizacijo, naj bi temeljito redefinirale evropsko upravno pravo in ga močno približale anglosaškemu. Sinonim za globalizacijo $v$ pravnem prostoru naj bi bila amerikanizacija evropskega prava. Pomembne so tudi spremembe $v$ konceptu Evropske unije, ki se počasi razvija tudi $\checkmark$ bolj izrazito politično integracijo. Velik premik je bil dosežen z zadnjimi spremembami evropskih ustavnih besedil $\vee$ Nici, kjer jim je bila prvič dodana tudi listina o temeljnih pravicah in svoboščinah. Zaradi tega EU počasi pridobiva tudi značaj močnejše politične tvorbe, kar še dodatno utrjuje položaj posameznika nasproti javni oblasti. S tega vidika so pomembne tudi spremembe nekaterih drugih določb Evropske pogodbe (npr. čl. 255), ki posameznikom dajejo pravico do dostopa do aktov Evropske unije, kot tudi spremembe $\vee$ poglavju o zaščiti potrošnikov, ki posamezniku prav tako jamči pravico do informiranosti, izobraževanja in do samoorganizacije za zaščito lastnih interesov.

Ne glede na povedano pa je preuranjeno trditi, da Evropa povsem prevzema ameriški model in koncept upravnega prava. Vplivi so sicer očitni, kljub temu pa ostajajo pomembne razlike. Z opisanimi spremembami se dejansko krepi položaj institucij, ki niso najbolj značilne za evropsko državno upravo. Tu mislim predvsem na neodvisne agencije in komisije pa tudi na naraščajoči pomen sodstva pri nadzoru ne samo zakonitosti, ampak tudi primernosti sprejetih upravnih odločitev. Primerjava evropskega in ameriškega sodstva pri nadzoru uprave jasno pokaže, da je ameriško sodstvo tu še vedno bistveno močnejše in bolj agresivno kot evropsko. Pravice posameznika v Evropi sicer postajajo pomembnejše, so pa še vedno bistveno manj poudarjene kot $v$ anglosaškem upravnem pravu. Evropska državna uprava tako doživlja pomembne in korenite spremembe, vendar jih prilagaja svojim, evropskim, značilnostim in posebnostim. Zato so ocene o konvergenci med anglosaškim in evropskim upravnim pravom preuranjene in tvegane.

\section{Zaključek: trdoživost evropskega modela}

Evropska pravila, globalizacija in drugi trendi $v$ svetu zelo pomembno vplivajo na strukturo in način delovanja državne uprave. Vpliv mednarodnih pravil, politik, dogovorov, praks na državno upravo izrazito narašča. Vendar v nasprotju z zagovorniki teze o konvergenci različnih ureditev, do katere naj bi pripeljala globalizacija, dejstva kažejo drugačno podobo. Pomembna ugotovitev je predvsem, da vsi ti 
trendi ne pomenijo odprave razlik med nacionalnimi državnimi upravami. Različne države sicer sledijo splošnim trendom, uporabljajo podobne metode reforme državne uprave, vendar rezultati kljub temu ostajajo različni. Nekateri splošni trendi so kot načela navzoči praktično $v$ vseh državah, vendar jih vlade uresničujejo na različne načine. Ne glede na premike $\vee$ smeri splošnih trendov med državami ostajajo pomembne razlike. Kot opozarja Vogel, še vedno lahko govorimo o različnih nacionalnih slogih oziroma modelih regulacije. Načela, usmeritve, ideologije, ki so sicer sprejete globalno, morajo biti implementirane $v$ določenem lokalnem okolju. Zaradi tega so vedno določene z značilnostmi nacionalne politične kulture, delitvijo političnega prostora, specifičnostmi pravne tradicije itd. Na takšno pogojenost institucij z lokalnimi dejavniki opozarja tudi historični institucionalizem, ki poudarja pomen konteksta, zgodovine, politike in drugih dejavnikov na razvoj institucij. Te nikoli ne nastajajo $v$ vakuumu. Zaradi tega je problematična Majonejeva teza o nastajanju novega modela regulatorne države. Majone sicer pravilno opiše številne skupne značilnosti evropskih držav, ki nastajajo kot posledica globalizacije in evropeizacije državnih uprav, vendar prehitro sklepa, da to že pomeni opustitev prejšnjega modela in nastanek novega. Bolj točna ocena bi bila, da se model intervencijske države prepleta z nekaterimi sestavinami novega načina regulacije, nikakor pa ne, da nov model $v$ celoti prevzema vlogo starega. Državna uprava ostaja tesno povezana z nacionalnim kontekstom, $v$ katerem deluje, zato je težko pričakovati, da bi lahko evropska integracija in globalizacija to značilnost v celoti odpravili ali spremenili.

Bojan Bugarič, rojen leta 1965, docent na Pravni fakulteti v Ljubljani. Po diplomi na Univerzi v Ljubljani nadaljeval študij na EUI, Firence (1992), UCLA Law School (magisterij), Univerisity of Wisconsin (doktorat), Harvard University. Od leta 1998 do leta 2000 gostujoči profesor na UCLA Law School, 2001 gostujoči profesor na Univerzi v Trentu, Italija. Od leta 2000 do 2004 državni sekretar MNZ, RS. V letu 2005 gostujoči profesor na UCLA Law School.

\section{Literatura}

- $\quad$ Berger, S. Dore, R. (1996): National Diversity and Global Capitalism. Cornell University Press, Ithaca.

- Bugarič, B. (1995): Ustavno sodstvo in (ali) parlamentarna demokracija: o doktrinah pravnega interesa in političnih vprašanj, Zbornik znanstvenih razprav Pravne fakultete Univerze v Ljubljani, LV, 43-66.

- Dicey, A. (1915): Introduction to the Study of the Law of the Constitution. Liberty Fund, Indianapolis.

- Garrett, G. (1998): Partisan Politics in the Global Economy. Cambridge University Press, Cambridge. 


\section{Bojan Bugarič \\ Evropsko upravno pravo: trendi in izzivi}

- Harlow, C. (1998): European Administrative Law and the Global Challenge, v Craig, Paul, deBurca, Grainne, ur., The Evolution of EU Law. Oxford University Press, Oxford.

- Hirst, P., Thompson, G. (1999): Globalization in Question. Polity Press, Cambridge.

- Hodge, G. (1996): Increasing Government Efficiency by Contracting Out Functions: An International Review of Performance Evidence, paper.

- John, P. (2001): Local Governance in Western Europe. Sage Publications.

- Parker, D. (1999): Privatization in the European Union: A Critical Assesment of its Development, Rationale and Consequences, Economic and Industrial Democracy, vol.20, str. 9-38.

- Pollitt, C. (2003): Decentralisation. A central concept in contemporary public management, EGPA, Oeiras, Portugal, 3-6/09/2003.

- Kamarck, E. (2000): Globalization and Public Administration Reform, v Nye, Joseph, Donahue, John, ur., Governance in a Globalizing World. Brookings Institution Press, Washington.

- Kagan, R. (2003): Adversarial Legalism, The American Way of Law. Harvard Universtiy Press, Cambridge.

- Majone, G. (1997): From the Positive to the Regulatory State: Causes and Consequences of Changes in the Mode of Governance. Journal of Public Policy, 17, 2, str. 139-167.

- Streeck, W. (1994): Neo-Voluntarism: A New European Social Policy Regime? European Law Journal, 1,1, str. 31-59.

- Stewart, R. (1975): The Reformation of American Administrative Law, Harvard Law Review, $88,8$.

- Schwartz, B. (1991): Administrative Law, 3rd Edition. Little Brown and Company, Boston.

- $\quad$ Šturm, L. (1998): Vezanost uprave na zakon, Javna uprava, 1, 34, str. 7-33.

- Thatcher, M., Stone Sweet, A. (2002): The Politics of Delegation: Non-Majoritarian Institutions in Europe. West European Politics (special issue), 25, 1, str. 1-220.

- Vogel, D. (1986): National Styles of Regulation. Cornell University Press, Ithaca.

- Vogel, S. (1996): Freer Markets, More Rules: Regulatory Reforms in Advanced Industrial Countries. Cornell University Press, Ithaca.

- Wilson, J. Q, (1989): Bureaucracy: What Government Agencies Do and Why They Do It. Basic Books.

- Wright, V. (1994): Reshaping the State: The Implications for Public Administration. West European Politics, 17, 3, str. 102-129.

- Ziller, J. (2001): European Models of Government: Towards a Patchwork with Missing Pieces. Parliamentary Afffairs, 54, str. 102-119. 


\section{SUMMARY}

\section{European Administrative Law: Trends and Challenges}

According to a widely shared view, globalization represents a new "invisible hand" that has been radically changing the relationships between international markets, national economies, and regulatory (legal) institutions and rules supervising both international and domestic markets. In an increasingly globalized and interdependent world, national economies are under strong pressure to adopt the best available economic and political institutions. Their potential failure to adjust to these new demands of global markets would perpetuate if not accelerate their loss of international competitiveness. For example, rigid and inefficient (scelortic) economic and political institutions are usually blamed for weak economic performance of many European economies. More particularly, the European welfare state, known for its generous and extensive legal protection of rights of unemployed workers and pensioners is blamed for its negative effect on the economic performance of many European economies. Again, deregulation, privatization, and reduction of benefits are perceived as a right solution for overburdened and scelortic European welfare states. On the other hand, the American model of regulatory state is then juxtaposed as an example of a more efficient and superior economic and political design. Moreover, after the collapse of the communist regimes, other third world nationalist experiments, and after the recent crisis of East Asian "tigers", "the regulatory state" is arguably the only game in town, i.e. the only available alternative in the world today. In short, superiority of more liberal market economies (LMEs), particularly those of the US economy, over coordinated (organized) market economies (CMEs) should therefore necessitate a profound change of inefficient European legal institutions. Because of that, Europe has a very limited range of options. It can either emulate more efficient US legal institutions or stick with its current inefficient legal arrangements. This view of globalization is called a strong convergence thesis.

Increasing openness of trade for goods, services and capital does not change only economic and political institutions. Legal regimes are an essential part of any well-functioning national economy. Not surprisingly, they too come under the pressure of global markets: in order to become competitive in an integrating world economy, national economies have to change not only their economic policy and political institutions but also their respective legal regimes. 
Bojan Bugarič

Evropsko upravno pravo: trendi in izzivi

What are the consequences of these changes for comparative law? An old view, portraying civil law and common law legal traditions as utterly different, if not incompatible, has given way to a new generation of scholarship, which sees more similarities and fewer differences, and which talks about convergence of theses two legal traditions. These scholars argue that there is a deep and elective affinity between the quality of the US legal system and the superior economic performance of the American economy. Some European scholars have recently argued that Europe is moving from its traditional model of "interventionist" administrative state to the US model of regulatory state emphasizing depoliticized and procedural rule making by independent agencies and judicial tribunals. The regulatory state represents a model of regulation where state interventionism, public ownership of utilities and strategic industries give way to private initiative. Markets and not states are seen as a solution. Privatization and deregulation of those public firms and industries is offered as a model for reform. According to this view, globalization means nothing less than almost complete convergence of legal regimes toward a single set of the available legal institutions best, which means, by and large, the Americanization of European administrative law. In short, the superiority of liberal market economies (LMEs), particularly of the US economy, over coordinated (more regulated) market economies (CMEs) should accordingly also necessitate a profound change of inefficient European legal institutions. As a result of all these changes and pressures, Europe has a very limited range of options. It can either emulate more efficient US legal institutions or stick with its current inefficient legal arrangements. The conclusion is pretty obvious: in order to compete with "the regulatory state", Europe has to shed many of its traditional legal rules and replace them with more efficient rules that can be borrowed from the US legal system.

Is convergence the only available path? Are there really no other choices? Does globalization really "produce" or "cause" the convergence among various legal regimes? Is its impact on economic and legal institutions as straightforward as argued by the proponents of the strong convergence thesis? How do international and domestic economic and legal institutions interact in a global economy? And last but not least, what is the role of legal rules and institutions in this story? We use the example of administrative law. In contrast with other approaches, our approach avoids potential dangers of oversimplification which are likely if we focus only on one field or one part of law. Here we follow a recent theoretical work by Peter Hall and others, who argue that modern market economies are organized around certain basic principles and practices which represent distinct types of what they call "varieties of 
capitalism" (LME, CME), they are bundled, and they cluster internally on several dimensions. Different types of regulatory regime states correspond to different types of market economies.

The conclusion is that although we witness a dramatic convergence of administrative models on a symbolic level, there is much more divergence in a real world. Administrative law is still strongly bound by national politics, legal institutions and other cultural factors. 